\title{
GIS in pre-census mapping of sampled rural and urban localities in Enugu north and south constituency: A sustainable pathway for census planning in Enugu State.
}

\author{
Chukwuemeka A. Onyekwelu1, Nnabugwu O. Uluocha2, \\ \& Alabi S. Soneye2 \\ ${ }^{1}$ Department of Geography, University of Nigeria Nsukka \\ ${ }^{2}$ Department of Geography, University of Lagos, Akoka, Lagos \\ Email: anthony.onyekwelu@unn.edu.ng,
}

\begin{abstract}
Background: The recurring inaccuracy in census figures is attriutable to the lacuna in pre-census mapping.

Data Source and Method: Geographic Information System (GIS) tool was demonstrated for the 2006 pre-census enumeration area- (EA) mapping of 2 NPC analogue EAs of urban and rural localities in Enugu State. An I I-tier EA template and a satellite image-based Geographical Information Technology EA Framework were generated using the Arc GIS version 10.3. All NPC analogue EA maps were found to fall short of the 12 spatial quality parameters viz; completeness, logical consistency, topological consistency, positional, temporal and thematic accuracy, mathematical basis, reliability, geometric accuracy, modernity, cartographic design and scientific and social value.

Results: A checklist audit analysis indicates that road and building are dominant EA features.

Conclusion:The application of a Geo-spatial data bank infrastructure within a Constituency Land Information System (CLIS) was suggested to help in aligning the agency on a proper trajectory to meet the targets of sustainable development.
\end{abstract}

Keywords: enumeration area, constituency, foot print map, GIS, GIT map

\section{Introduction}

The term 'census' originated from the Latin word 'censere' which literally means to tax, assess or value. Population census is defined by the United Nations as the total process of collecting, compiling, evaluating, analyzing and publishing or otherwise disseminating demographic, economic and social data pertaining, to a specified time, to all persons in a country or in a well de-limited part of a country (United Nations, 20II).

Population census undoubtedly is an important issue of concern in Nigeria, since its size, and composition has far-reaching implications for change, development and the quality of life. Census exercises in Nigeria have "triggered political, social, ethnic, religious controversies, geo-political distrust and disputes that negatively affect nation building and sustainable development in the country. Population census is one of the fundamental tasks of the government. It has become a backdrop for government's political, economic and social policy formation. Population census is one of the key planning strategies towards sustainable development and progress of a nation. It provides answer to: How many we are " in terms of the total number of people living in the entire nation, -"Who we are?"" in terms of age, sex, education, occupation, economic activity and other crucial characteristics, as well as "Where we live" "in terms of housing and access to social amenities. The answers to these questions do provide numerical profile for planning and development within a nation by providing, expanding and sustaining the infrastructures that will enhance the quality of life of the people" (Ezeah, lyanda, and Nwangwu, 2013).

Amori $(200 \mathrm{I})$ is of the opinion that a census is expected to possess seven attributes in line with th.e recommendation of the United Nations, and they are namely: Universality, Territoriality, Simultaneity, Government Sponsorship, Defined periodicity, Official Publishing, Technical Input. Every individual must be counted irrespective of race, status or origin.

- Territoriality- the exercise must cover a geographical entity with defined boundaries.

- Simultaneity- the head count must take place within a specified time frame.

- Government Sponsorship- due to the huge financial cost it should be borne by the government.

- Defined Periodicity- Regular census at specific intervals of ten years to ensure the availability 
of comparable information in a fixed sequence such that is possible to examine the past, accurately describe the present and predict the future

- Official Publishing for public consumption Technical Input - this implies the best application of most modern means of data acquisition and remote Sensing data

\section{Background to the study}

The knowledge of a nation's total population, gender and age group structure as well as direction of population growth through reliable and regular census counts can provide base-line data for budget planning, equitable resource allocation and rapid development (Ezeah, lyanda, and Nwangwu, 20I3). In a study of Nigerian population by Pai (20/3), he observed that a total of 15 census counts have been witnessed in Nigeria between the first exercise carried out in 1866 and the last in 2006 (Pai, 2006).

National Population Commission (2007) its publication records that Lagos Island and some parts of the mainland were covered in the first 5 counts. In 1906 a total number of 16.06 million persons were enumerated. The first amalgamation that included Lagos Colony and the Southern Protectorate took place in 1906. This was followed by the census exercise of select parts of the Southern Protectorate in 1911 which pioneered a 10-year span census regime in Nigeria. A decade later in 1921, 18.72 million persons were enumerated though the exercise was based mainly on tax records of the country which excluded the youthful population whom basically constitute a good percentage of nontax payers (NPC 2007).

The 1931 census was hampered in major towns of Eastern region due to anti-tax protests and riots in Calabar and Owerri provinces in the then Eastern region and the locust invasion which affected some parts of the Northern provinces in the same year brought total population figure to 19.93 million.(National Population Commission 2007) No population census was conducted in 194I apparently due to the 2nd World War. The 1952/1953 population census was the first modern, national and carefully planned census in Nigeria. This however took place without applying the principle of simultaneity. In Northern Nigeria census was conducted between May and July, 1952 while the West and Mid-West counts took place in December 1952 and January 1953 respectively. Another round of census was conducted in the Eastern region between May and August, 1953. This non-adherence to the principle of simultaneity in the conduct of census in the four regions made the comparability of data between one region and another difficult. Furthermore, the disruption of the Second World
War made people suspicious of the intention of the exercise and therefore many people did not submit themselves for enumeration. This meant that the exercise was characterized by gross under enumeration. The records thus show that within this period (1950-1953) a total of 30.42 million persons were recorded (National Population Commission, 2007). In May 1962, the census exercise took place simultaneously in the whole country. There was adequate public enlightenment before the exercise but unfortunately the results were rejected by the government on grounds of high politicization. This position of the government snowballed into another census round in the following year- 1963. An exercise many opposed and claimed was a product of negotiation rather than default by the government and this led to a second cancellation of the 1973 census results. The reason given for the cancellation was on the grounds that there was a deliberate attempt at falsification of total figures for political and or ethnic advantages.

The total census figure for Nigeria in 1991 after the census exercise which took place simultaneously from 27 th November to 2nd December 1991, is put at 88.99 million persons. This figure has remained the most reliable census figure and a reference point for years. The establishment ot Decree No. 23 in the 1989 constitution amendment gave rise to the division of the country into enumeration areas for the conduct of the 199| census exercise.

Ten years after this (in 200I) no census count was witnessed because of the governments illpreparedness. Then in 2006 a census count was simultaneously conducted in March and the total census figure for the country was put at I 40 million people. Machine readable forms (OMR/OCR/ICR) were used to record information from respondents. (NPC Manual, 2006)

Accurate spatial datasets and complete attribute details are the most crucial signs of a successful census survey. The smallest administrative unit for census survey is the family unit i.e. the household, while the smallest administrative area for a census survey is the enumeration area, made up of a group of households. A household consists of a person or a group of persons living together usually under the same roof or in the same building/compound who share the same food and recognize themselves as a social unit with a head of a household.

There are 8 types of household namely: Regular household, Institutional household, Homeless household, Homeless persons. Nomadic household, Transient persons/household, Fishing and Hunting population, and Census functionaries. The preparatory activities that precede the census activities are: 
- Enumeration Area Demarcation (EAD)

instruments

- $\quad$ Pre-test and trail census

- Soliciting support of government at all levels, political leaders and donor agencies etc.

- Recruitment and Training of Field Staff

- Data Capture, processing and analysis.

Given the persistent problem of inadequate spatial aggregation of households and persons there-in a number of challenges of the National Population Commission were identified by the author during oral interview and observation of census spatial datasets and they are as follows;

(I) Use of free-hand analogue maps as enumeration area (EA) documents evident in the use of NPC free- hand EA analogue maps

(2) The use of un-updated cadastral maps for Enugu North/South constituency of I:2,500 scale; and the year of production range from 1960-1970's as a guide to EA demarcation in the urban area

(3) Non-existence of administrative maps of the rural areas evident in the use of free-hand analogue NPC EA maps

(4) Use of un-updated administrative maps of urban areas used for the 2006 census evident in freehand NPC analogue EA maps of uwani

(5) Poor coverage by Land Sat images of housing units due to the effect of tree canopy on spatial features and objects on ground which necessitated the use of GPS instrument by author to capture location details of EA in ngwo rural area.

In all the head-counts after Independence (1960) the evidence of a yawning gap in the link of geodemographic units (EA) and population clusters is real, culminating in a disconnect between declared figures and actual figures on ground. In Nigeria, the population of each geo-political zone or state is a paramount yardstick for deciding how much of the country's earnings is allocated to same.

This enumeration area (EA) mapping exercise also known as pre-census mapping involves demarcating the smallest administrative units called EAs which usually precedes the main census count. This research is of great importance because the Nigerian government has not been able to apply a synoptic formula for aggregating land units (EAs) and integrating them into a holistic national frame that will provide wholesomeness to spatial data across local government areas, constituencies and States. EA mapping is an agglomeration of geo-demographic units along boundaries of States. This exercise takes the form of a national geographic frame that integrates all spatial shape-files from individual states to guide the enumerator on the field. Any error at this level sends ripple effects across the entire geographic frame and as such translates to omission of settlements.

All past census exercises in Nigeria have employed analogue hand drawn EA maps in executing population survey with inclusion of the 2006 census exercise whereas a sustainable GIS mapping method could have been deployed. GIS mapping of EAs provides an elixir to enumeration area mapping in Nigeria. In order to meet the sustainable development goal I; no poverty, goal 2; zero hunger, goal 8; decent work and economic growth, goal 9; industry, Innovation and Infrastructure, goal 10; reduced inequalities, goal $\mathrm{II}$; sustainable cities and communities and goal 12; responsible consumption and production. This underlies the essence of this paper.

The study area is Enugu State and the 2 sampled areas are ngwo and uwani Enugu North and South constituencies respectively. 


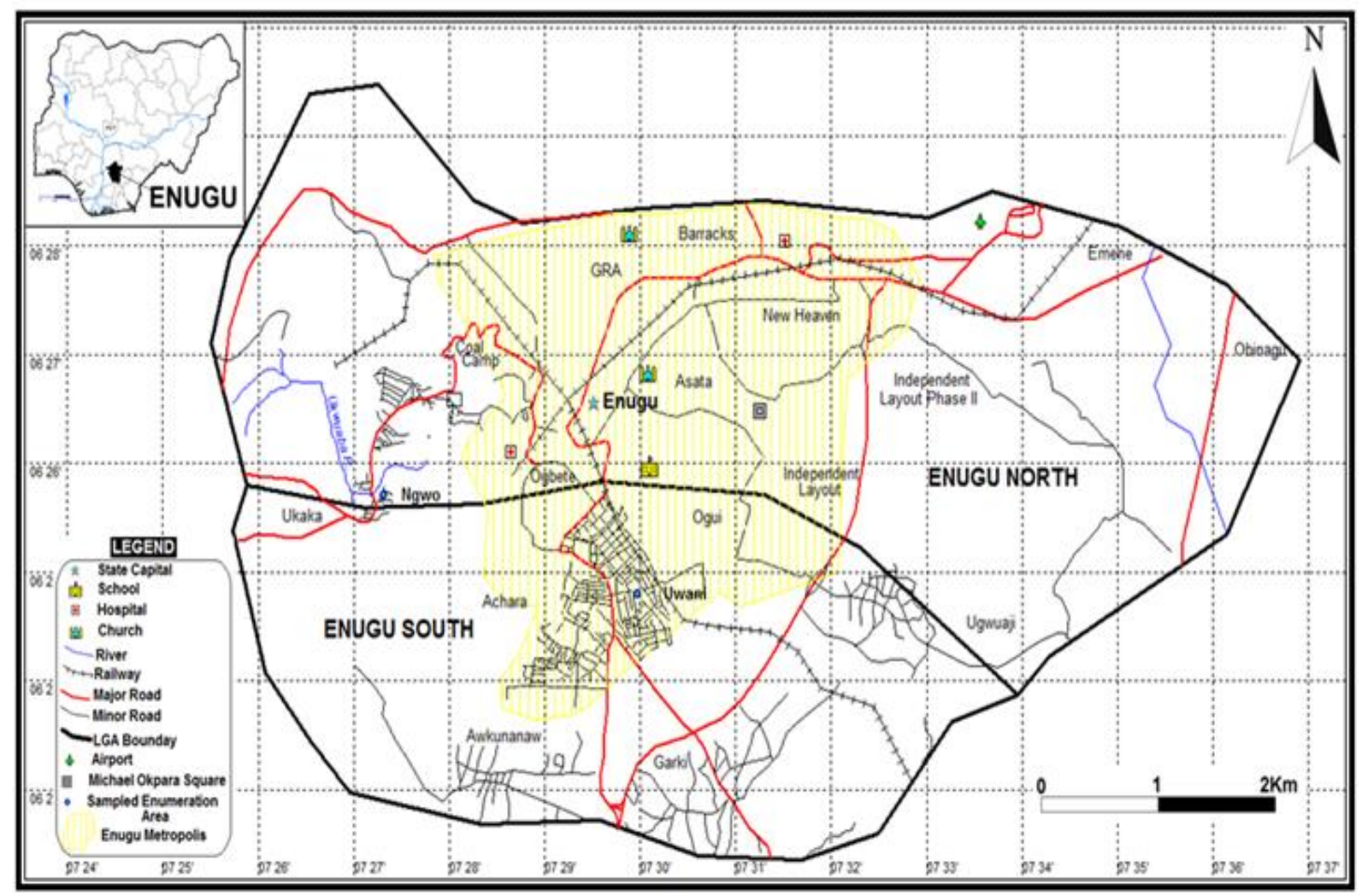

Fig. I: Study Area - Uwani and Ngwo in Enugu South and North Constituencies

Source: Digital Globe 2017

This work demonstrates the capacity of GIS technology in pre-census mapping as an alternative paradigm to analogue NPC EA maps in Enugu State.

The objectives are as follows:

(I) To determine the status of EA mapping and challenges thereof

(2) To develop an EA Template of Enugu State

(3) To deploy a Hi-resolution satellite imagery in creating EAs of sampled areas

(4) To assess the quality and sustainability of GIT EAs of sampled areas

\section{Literature review}

Mapping has since taken a paradigm shift from an analogue exercise to digital, with attributes like: metadata information, database platforms, animation, data analysis and sequential query language as key attractions. A map is a graphic representation of the Earth on a scale. Maps represent snapshots of population distribution, density and structure. It is one tool that best describes synoptic population dimensions. The size of spatial entities on map is dependent on map scale, even the smallest entity can not be depicted without recourse to map scale. The rule of the thumb in symbolization is that anything smaller than $0.5 \mathrm{~mm}$ cannot be perceptible on a map (Srivastava 2013). One of the most crucial prerequisites for all censuses is the availability of current base maps. In Enugu State a number of issues concerning the nature of base map data which form the core data are very pertinent at this stage.

In this direction, a classical author, Morris (197I) describes the relationship between the sign vehicle, 'designatum' and 'interpretant' as equivalent to the syntactic- the ordered relationship between symbols, semantics - the relationship between symbols and what they denote while pragmatics as the relationship between the symbol and the interpreter respectively.

Dwelling on census maps, Oladayiye (2000), is of the opinion that inputs of pre-census activities "fundamentally need upgrading of the status of the National Population Commission"s organizations (2006) data sets. This is evident in the crude nature of the primary data set upon which the bulk of the census activities rest. These data that are either below standard or too far in-between to be relied upon, result to non- suitability of the data set for any well- meaning pre-census activity." This situation gives a 'bite' to the reason why census outcomes have never been holistic in nature which buttresses the widespread poverty, hunger, poor health system poor education system, lack of potable water upscale unemployment e.t.c

The EA database serves as baseline data in addressing sustainable targets $1,2,3 \& 4$. In the same vein, Dada (20/2), in studying analogue maps demonstrates the relevance of maps to GIS development in Nigeria, and submits that NPC EA and SA maps have varying degrees of accuracy and 
scale and are best regarded as sketch maps since they were compiled by people who are not professionally trained. Map symbols carry the message of the map maker across to the end-user.

Geo-Space (2002) International applied digital aerial photography to generate base maps for 970 areas scattered all over South Africa. The biggest asset of aerial photography over other modes of data acquisition is the flexibility of its pixel resolution in the creation of imagery. The EDAC project applied 'digital aerial imagery to produce housing unit counts in ten of the most historically under-counted countries in New Mexico.' EDAC in collaboration with 'Bureau of Business and Economic Research (BBER) used digital imageries in interpretation and counts of housing structure within 3,500 census blocks.' Overall the 'program provided an additional 131,283 housing units not previously identified by the Census Bureau of Enumeration; an information that increased federal funding as much as $\$ 1$ I million per year' (EDAC 2008).

Wu and Murray (2007) in assessing the Zonal and pixel-based models of population estimation used Landsat ETM imagery over Columbus, Ohio.

Olorunfemi (1983) in his study of llorin asserted that the idea of monitoring changes with traditional methods of surveying showed that satellite remote sensing technology have proved to be of immense value for preparing accurate land use land cover maps and monitoring changes at regular intervals of time. In case of an inaccessible region, this technique is perhaps the only method of obtaining the required data an a cost and time-effective basis.

In the census mapping project of the 2006 Population and Housing Census of Lesotho SPOT $2.5 \mathrm{~m}$ natural colour super mode imagery was applied. Ethiopia has applied SPOT5 $2.5 \mathrm{~m}$ for their 2007 census because of it suitability for rural areas and less dense formal urban centers. (Geo-Spatial Resource Portal 2006).

In Nigeria, the National Population Commission in 2005 did acquire images of Very High Resolution for census count in 2006 but apparently due to lack of equipment and professional skill did not know how to put the satellite imageries into the right format in preparing the NPC EA maps for 2006 census.

Currently Very High Resolution images cover 90 major towns and cities. SPOT 5 was also acquired for the country at $94 \%$ coverage. (NPC 2007). Hardin and Shumway (2008) applied very high resolution remotely sensed data to gather intra urban population counts, to support urban decision- making in developing economies. They are of the opinion that moves driven by remotely sensed imagery are of the few economically viable alternatives available to countries with developing economies.
Lesotho in 2006 conducted its most recent population and housing Census using the latest technology in remote sensing and GIS. This involved total coverage SPOT $2.5 \mathrm{~m}$ natural colour satellite imagery, GPS and GIS. Preliminary E.A. demarcation was undertaken through image interpretation. In the end this modern approach resulted in a better quality production as well as saving about $20 \%$ when compared to the original budget of sketch maps(United Nations 2009).

In a study in Namibia census data was disseminated a lot of captured details from locations and structures around the country with GPS enabled PDAs, verified using two tools Geo-media and Arc GIS were stored in a GIS Database.

In 2006, Israel conducted a GIS and Population Household Census employing six processes:

(i) Geo-processes for data integration

(ii) Spatial Database and Metadata

(iii) Tracking data with missing data

(iv) Complementary data production

(v) Sampling

(vi) Management and control of field supplementary enumeration

Spatial analysis method for querying census data Namibia began its digital mapping and GIS program in its $200 \mathrm{I}$ and was faced with some challenges like initial lack of spatial data, boundary problems inaccessibility of some areas and lack of trained personnel. In 200I Namibia established a web-based GIS using Post-gress open-source software that will enable users to create their own maps. Data will be stored and accessed centrally using Oracle (United Nations 2009).

Mokgokolo (20I I), described enumeration area (EA) as the smallest entity into which the country is divided for census or survey enumeration. It is also the operational platform for data collection during the census that comprises the lowest level of geographic hierarchy of administrative and statistical units (United States Census Bureau, 2015). Eze and Igbokwe (2004), while studying the delineation and management of census enumeration areas in Enugu, agree that a vital component of census work is the delineation of statistical areas sometimes referred to as enumeration areas (EAs) for the field assignments and this lays the spatial foundation for the census datasets.

The enumeration area map production for the municipals or rural lands relies on systematic topographic maps produced at IBGE and Geographic Service Directorate of the Brazilian Army. Production is carried out through Semi-Automatic Municipal Maps Elaboration System (SisCart) from the topographical maps. This provides functionality in http://aps.jouranls.ac.za 
support of map projection and scale, geo-coding of topographic map sheet comprising municipal map, edge-matching between joining sheets, cropping of sheets following the municipality's perimeter and the editing of framework.

Urban area enumeration area map production relies on cadastral maps of scale 1:2000 to I:10,000.The technical innovations in 2007 Brazil census consist of the use of Personal Digital Assistants (PDA) integrated with GPS, enabled the creation of a database.

Cambodia carried out E.A. mapping and village boundary mapping as a part of its 2003 Health Survey Census GIS. E.A.s of not more than 120 households were delineated. Village questionnaires were used to produce E.A. Database. Among the functions of E.A. database were operations to label, check in, code, edit, perform data entry, verify and clean boundary data (United Nations 2009).

Stoter et al. (20/4) applied automated generalization work-flows to improve topographic mapping for GIS outcomes. In this line, Dinar et al (2015), agree that topographic map generalization and visualization using 'omission operator' in selection and 'shifting operator' in simplification and classification enhance faster accomplishment and easy distribution of end-products to stakeholders. Plans of towns and cities which are drawn to large scale can be used for EA delineation as well as special maps illustrating the physical features such as demonstrated by (Fasona and Omojola, 2009). Orongo (2013), in his study of topographic map generalization in Nairobi Kenya, showed that vector data and building data are the key workflow indices for pre-census mapping. These steps are invaluable in digital aerial photograph capture of rural areas where sustainable targets like;

(I) No Poverty,

(2,)Zero Hunger

(3) Good health and well being,

(4) quality education

(5) gender equality \&

(6) clean water and sanitation can be handled.

Geographic Information System provides for data input, data processing, analysis and data output. The procedure when applied to EA mapping supersedes the all other previous techniques applied in precensus mapping. It thus provides a nexus for spatial unit identification and location. Remotely Sensed Imaging in the form of Earth Resource Technology Satellite (ERTS) Spacecraft represent the first step in merging space and remote sensing technologies into a system of inventorying and managing the Earth's resources" (Mckelvey, 20l I). It is a sure pathway to sustainable development goals I-I7.
In his study Srivastava (20I3), re-echoes that in GIS and mapping, the map-scale is a key factor in generalization, geometry, legibility threshold, accuracy and relationship among entities-(a major drawback in all the NPC EA analogue maps). The level of generalization and exaggeration, geometric form of an entity (a city is either shown by a polygon or by a point). The map scale controls the positional accuracy and the level of uncertainty for an entity as well as the way real-world features are modeled to digital data-sets in the form of pixels, or by points, lines or polygons. Lastly, the relationship among spatial entities is controlled essentially by the mapscale a strong quality of interoperability.

Kugler et al (2018) in studying census and survey data applied Integrated Public Use Microdata Series (IPUMS) as a support platform for data integration to create interoperable datasets, user-friendly interfaces, comprehensive metadata and documentation. This procedure can easily enhance the processes that match accuracy with input data entries of aggregated EA spatial datasets to key into the purview of sustainable goals strategy.

Census taking in Nigeria, has a chequered history in that "population censuses held before and after independence have ended in national controversy, strong allegations of population falsification and in fact no general consensus among the populace as to the size of the total population of Nigeria" (Eniayejuni and Agoyi 20II).

The government has undoubtedly failed to harness the importance of population census for planning, progress and development, since previous censuses have been victims of intense elite contestation for political and economic power, accusation of regional bias and favouritism, popular distrust, resistance and widespread suspicion of the census results (Diamond, 1998).

Soneye and Akintuyi (20l3) observe that the nonavailability of basic data and resources are the prime cause of obsolete map products. Egharevba (2017) in his study attempted to establish the connection between population increase and democratic governance and discovered that policy makers have consistently failed to generate and adopt reliable demographic data a sign-post of failure in achieving sustainable goals.

The dividends of democracy are transmitted through the respective constituencies and in so doing, we feel the need to apply the same spatial yardstick to demarcation of enumeration area units. We advocate the demarcation of enumeration units along statutory boundaries of constituencies which bestrides a group of local government areas. This not only serves as permanent enumeration area units but also provide spatial units of identification and coding 
for subsequent census count. This is an information and technological age where and there is the need for transformation of the census exercise to embrace new technologies and to yield credible data for sustainable development in Nigeria.

The basic mapping procedure of the National Population Commission, in 2006 census count is the application of obsolete mapping data sets and use of non-professional technical staff in EA map production. Census is not complete until the information is passed to potential users and stakeholders. Information may be in table and reports or database. This information can be disseminated in 4 ways - paper publication, CD-ROM, DVD, and static web pages in Html, PDF and excel). United Nations (20II). Given the heterogeneity and complexity of Nigerian census datasets and the large population size of the country there's the need for the deployment of appropriate mechanisms such as geo-spatial technologies (remote sensing, GIS and the global positioning system) to ensure that maximum coverage is achieved (Onyekwelu and Ochege 2015) and minimal lapses are witnessed in the census exercise. A successful census is impossible without current and accurate constituency maps. fold:

The products of spatial data support are three

(i) Thematic maps showing population density and distribution, demographic characteristics, socioeconomic characteristics and household listing;

(ii) Digital geographic database showing shape files and attribute data and

(iii) Digital census atlases (United Nations, 20 I I).

In building a Geo-spatial database for census count, an administrative hierarchy, coding scheme, geo-coding linkage to geographical location latitude and longitude to individual addresses are all important (geo-targeting) (United Nations 20l0).

Obono and Omoluabi (20/4) studying the 'Technical and Political Aspects of the 2006 Nigerian Census' submit that like most post-independent censuses, there exists parameters, opportunities and motivation to manipulate the final results a recurring ideology in the psyche of political leaders in Nigeria which runs contrary to some sustainable targets. They focused mainly on the processes leading to the census outcomes and not the results per se.

Odimegwu (2013) submits that future censuses in Nigeria cannot yield expected desirable and credible data without the adoption of improved technology that way the country will be better positioned to attain sustainable goals. In a multi-faceted society like Nigeria where population size of each region is important in determining their political and economic status. The elite are often over-zealous about the value and importance of population census, and they always do anything, not only to enumerate all their people, but also engage in various illegalities: electoral violence, falsification and manipulation of population figures (Stallings, 2006) which is a dangerous path to tread if Nigeria wants to attain the sustainable goals.

Mberu and Eze (2017) in a study revealed the inevitable role of population factors in achieving key development goals in sub-Saharan Africa and suggested the need for interventions like voluntary family planning to avert poverty, maternal and child mortality and women empowerment. Gareene (2006) discovered that population growth in South Africa has some connection with the trend of nuptiality which is generally prevalent among the black population. This will certainly reduce poverty among the same group in line with goal I.

In the development of a National Policy Framework for census generally, Constituency Land Information System (CLIS) in geo-spatial datasets must be gathered in an accurate and holistic manner. Some countries use different criteria and methodologies for defining and managing EA boundaries that rarely coincide with geographical boundaries making it difficult to share accurate data spatiality with the same geographic area. It is believed that when EAs of a particular community are assigned community names, all like EAs are aggregated and delineated and to form the boundaries of respective communities (Wall, 2015). This process is followed by coding of the EAs and subsequent data integration to produce EA shape-files. These documents are products of a hi-profile resolution imagery with better accuracy than the analogue method providing solutions for sustainable targets
I, (no poverty)
2, (zero hunger)
3 , (good health and well being
4, (quality education)
5 , (gender equality)
6, (clean water and sanitation)
7, (affordable and clean energy)

8, (decent work and economic growth)

9, (industry, innovation and infrastructure)

10, (reduced inequalities)

II, (sustainable cities and communities)

I2, (responsible consumption and production),

13, (climate action),

14, (life below water)

16, (life on land) \&

17, (partnership for the goals).

Data et al (20/2) examines delineated census tracts (CTs) in the Census Metropolitan area of London, Ontario, Canada considering levels of compactness of CTs and their population-based and 
area-based uniformity which has been achieved at the expense of uniformity in population and areal sizes.

Homogeneous" applied the method of dasymetric mapping in removing undeveloped areas (such as areas covered by other bodies of water, wetlands, or forests) from the census blocks, changing their shape and reducing their size. This method undoubtedly fully captures the framework for strategies to meet sustainable goals $\mathrm{I}-\mathrm{I} 2$.

\section{Theoretical/conceptual framework}

Robinson and Petchenik (1976), in their study of map perception also held the view that map reading rested on cognitive psychology, thus advancing the notion of such classical scholars.

Samreen's (20/3), study of 'perception in map visualization`shows that a viewer can take advantage
The US Department of Homeland Security (FEMA 20I5) on "Hazus-MH Data Inventories: Dasymetric vs of the strengths of the visual system and avoid interference, in order to improve the quantity and quality of displayed information. Zyszkowska (20I5), in a study revealed that the scope of cartographic communication and map perception was regarded as a step in the process of information transfer, and therefore a process of reading, is understood as the relationship between stimulus and response. The assumption is that information acquired during map processing is retained in the "memory storage" and the encoding that occurs in the course of map reading is subject to quantitative changes. The work adopts the concept in Robinson et al. (1978), describes a cartographic communication model developed by Board (1962) as shown below.

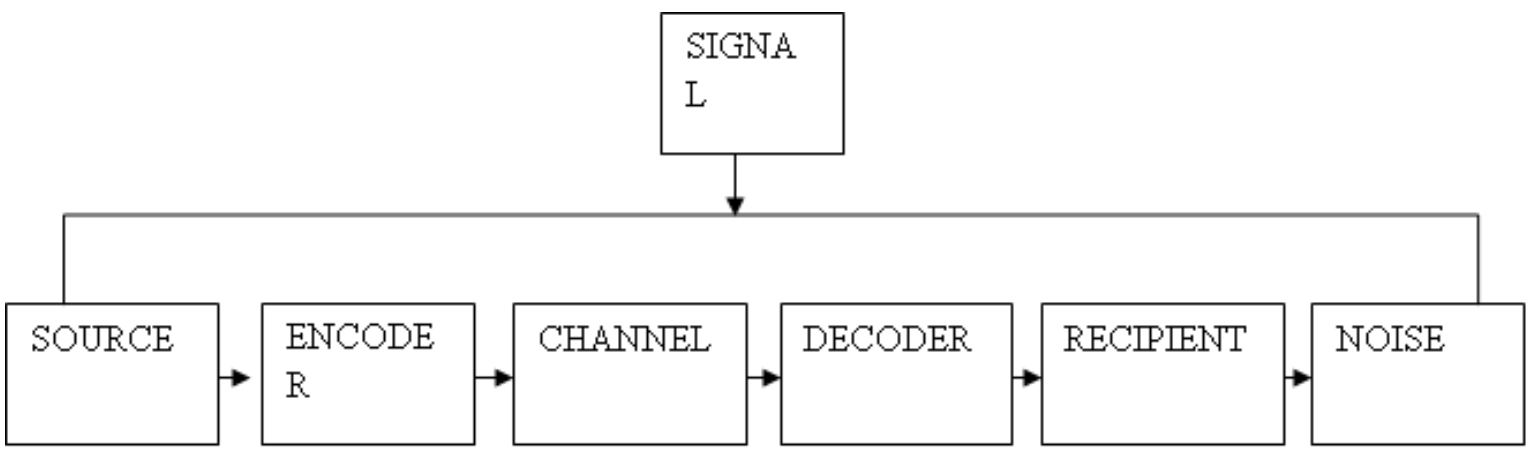

Fig. 2: Cartographic Communication Model (Source: Robinson, Sale and Morrison (1978)).

'Source' means the real world, 'Encoder' is the symbolism of the map, the 'Signal' is the two dimensional pattern created by the symbols, the 'Channel' is the light rays transmitted to the map, the 'Noise' is anything in the signal or channel that interferes with the transmission, the 'Decoder' is the eye-mind mechanism of the recipient.

\section{Data and methods:}

Enugu State is located between Latitudes 5050 ' $\mathrm{N}$ and $7030^{\prime} \mathrm{N}$ and Longitudes 6050' $\mathrm{E}$ and 7050' $\mathrm{E}$. It was the former capital city of Eastern Region (1963-67), East Central State (1967-76), Anambra State (1973199I) and Enugu State (199| till date). It is the oldest city in the south-east geopolitical zone of Nigeria. It is bordered by five other States: in the northwest by Kogi State, in the northeast by Benue State, the south

by Abia State, in the south-east by Cross River State and south-west by Anambra State.

The restriction to only two NPC analogue EAs for the study by the custodians has necessitated a purposive sample of Ngwo (rural) and Uwani (urban) case studies in Enugu North/South Constituency respectively. The State has three major urban centres - Enugu, Nsukka and Oji River. There are a total of 17 LGAs.
Enugu, the capital, is a town $65 \mathrm{~km}$ east of Awka capital of Anambra State and $90 \mathrm{~km}$ northeast from Onitsha the commercial hub of Anambra State. The major towns in the State comprise Udi, Nsukka, Enugu-Ezike, Oji River, Agbani, Nkwo-Nike, Ogbede, Obollo Afor, Ninth-mile and Awgu. The 8 State Constituencies are:

(i) Enugu North \& South

(ii) Enugu East \& Isi-Uzo

(iii) Nkanu East \& West

(iv) Udenu \& Igbo-Eze North

(v) Nsukka \& Igboeze South

(vi) Uzo- Uwani \& Igbo-Etiti

(vii) Oji River \& Ani nri /Agwu

(viii) Ezeagu \& Udi.

The population of the State is put at 3,257,298 persons with I,624,202 males and I,633,096 females (NPC, 2007). The dwellers in the urban area are mainly civil servants, artisans and business men while a good majority in the rural areas are subsistence farmers. The study area consists of 2 constituencies of Enugu North and South constituency which were purposively selected for the study due to the highly classified nature of NPC EA maps. One rural and one urban area in both constituencies of Enugu North and Enugu South respectively were studied. NPC analogue EAs of Patience Ozokwor (rural) in Enugu 
North and Ngwo Park (urban) in Enugu South respectively were acquired for the study.

These spatial data are Quick-Bird satellite imagery of uwani, administrative map of uwani, topographical map of ngwo, cadastral map of uwani, Land Sat imagery was of limited use in ngwo rural area because of canopy hindrance like wise the aerial photograph of the same locality.(see Table I ).

Table I : EA spatial data sources for the Uwani and Ngwo localities

\begin{tabular}{|c|l|}
\hline S/No. & \multicolumn{1}{|c|}{ Data Type } \\
\hline I & $\begin{array}{l}\text { Topographical map of ngwo } \\
\text { Date: I } 960-1963 \\
\text { Scale: I:50,000/I:100,000 } \\
\text { un-updated topogragraphic map of ngwo. on-line topographical maps were generated for the } \\
\text { study }\end{array}$ \\
\hline $\mathbf{2}$ & $\begin{array}{l}\text { Cadastral map of uwani } \\
\text { Date: 1960-1970 } \\
\text { Scale: I:2,500 } \\
\text { un-updated cadastral map of uwani. } \\
\text { on-line google map of uwani was generated for the study. }\end{array}$ \\
\hline $\mathbf{3}$ & $\begin{array}{l}\text { Administrative map of uwani } \\
\text { Date: 1990-2000 } \\
\text { Scale: 1:5,000 } \\
\text { un-updated administrative map of uwani. on-line google map of uwani was generated for the study. }\end{array}$ \\
\hline $\mathbf{4}$ & $\begin{array}{l}\text { Aerial photograph of ngwo } \\
\text { Date: 2004 } \\
\text { Scale: I:3,000 } \\
\text { limited usefulness in rural locality due to canopy hindrance. on-line google earth imagery of ngwo } \\
\text { was generated }\end{array}$ \\
\hline $\mathbf{5}$ & $\begin{array}{l}\text { Land Sat I imagery of ngwo } \\
\text { Date: } 2005 \\
\text { Scale: I:36,000 } \\
\text { limited usefulness in the rural locality due to canopy hindrance on-line google earth imagery of } \\
\text { ngwo }\end{array}$ \\
\hline
\end{tabular}

Source: National Population Commission, Abuja, 2016

The geo-corrected Quick-Bird imagery with an estimated published spatial accuracy of $14 \mathrm{~m}$ root mean square error (RMSE). was exported to an Arc GIS environment. Topographical maps of different dates and attributes were created and stored using the Arc GIS software package version 10.3. The Quick Bird imagery was enhanced using ERDAS Imagine image processing software, to facilitate the digitizing. The Geo-referencing was performed using the Arc GIS 10.3 software package.

Due to unavailability of location details for the ngwo locality in the NPC analogue EA map we had to resort to GPS survey of the EA with PDAs which enabled us generate an online topographic map, Google Earth image and Google map-base for the EA For this locality. re-projection and map/image

NPC. A total of forty copies of questionnaire were administered to entire personnel of the cartographic and census planning sections of the National $4|9|$ overlays were done within Arc GIS environment. Further digitizing was performed using GPS Track Maker software and a combination of on-line Google Earth and Google Map layers. We applied the use of Arc GIS 10.3 for geo-referencing. We notice a sharp departure in map quality and design, geo-referencing, structure and shape of buildings, dimension of buildings, roads, streets, landmarks length, and shape of spatial features and objects point line and areal feature depiction and description. Also rendition of place-names, depiction of cartographic symbols, description of spatial features, typographic hierarchy are more professionally rendered in footprint and GIT maps.

An oral interview was conducted with staff of the cartographic and census planning sections of the Population Commission to ascertain the quality and sustainability of the generated GIT maps. The respondents were drawn from the NPC http://aps.jouranls.ac.za 
cartographic and census planning \& research departments. A checklist was developed to matchmake the observed EA features on ground with those found in footprint and GIT maps of uwani and ngwo. This was subjected to a frequency test to ascertain the frequency of occurrence of the checklist features A range of cartographic symbolization inconsistencies were noticed as follows; total absence of coordinates in all analogue EA maps, scale, typography, name placement, line symbolization, point symbolization, bounding line delineation and map design.

In assessment of the map accuracy the map scales of the foot print and GIT map of (ngwo park) uwani and (patience ozokwor) ngwo were used as yardsticks to determine map feature dimensions like road length and street length. The measured values of street and road lengths of NPC analogue EA maps of uwani and ngwo when compared with similar street and road length values on footprint and GIT EA maps of uwani and ngwo revealed disparate values.

For large urban EAs the population size per EA ranges between 250-350 persons per EA which amounts to an average population size of 300 persons per EA. In majority of other EAs the population size ranges from 200-300 persons per EA which amounts to an average population size of 250 persons per EA. (NPC 2006). The urban ward household $(\mathrm{HH})$ size ranges between $4 . \mathrm{I}$ and 5.2 persons per $\mathrm{HH}$ which gives us an average figure of 4.65 persons per $\mathrm{HH}$ or approximately 5 persons per household. In the rural ward the population size ranges from 150-200 persons per EA which amounts to an average population size of 175 persons per EA. In the rural ward the average household size ranges between 5.2 and 7.I persons per $\mathrm{HH}$ which amounts to an average figure of 6.15 persons per $\mathrm{HH}$ or approximately 6 persons per HH. (NPC 2006). Enugu State has a total of 13,977 enumeration areas (NPC 2006).

These derived spatial data of EA maps of uwani and ngwo localities show in detail units of land and in the GIS spatial data format reveal vector and raster data shape-files. This GIS method ensures a more holistic, detailed and accurate capture of spatial features and objects than the analogue method of delineating enumeration areas applied by the NPC in 2006 census survey. This GIS procedure demonstrates the importance of using the best tool in delineating EA units. This method will surely counteract omissions and repeated-counting among the enumerators in their assignments in pre-census survey of Enugu State. An II- tier Census Geography Framework was advanced after a careful observation of the pattern of dwelling units/housing during field study. This is with special regard to the rural area on how kindred and filial ties shape the pattern of housing and census geography of same.(See Table 2 ).

Table 2 Census geography of Enugu State framework

\begin{tabular}{|ll|}
\hline Urban & Rural \\
\hline Household & Household \\
\hline Building Footprint & Dwelling Unit/Compound \\
\hline Enumeration Area & Kindred \\
\hline Supervisory Area (ward) & Enumeration Area \\
\hline Locality & Supervisory Area (ward) \\
\hline Locality & Locality \\
\hline State Constituency & State Constituency \\
\hline State & State \\
\hline Federal Constituency & Federal Constituency \\
\hline
\end{tabular}




\begin{tabular}{|ll|}
\hline Geo-political Zone & Geo-Political Zone \\
\hline Country & Country \\
\hline
\end{tabular}

Source: field work 2018

GIS EA mapping framework was generated for the urban and rural localities.

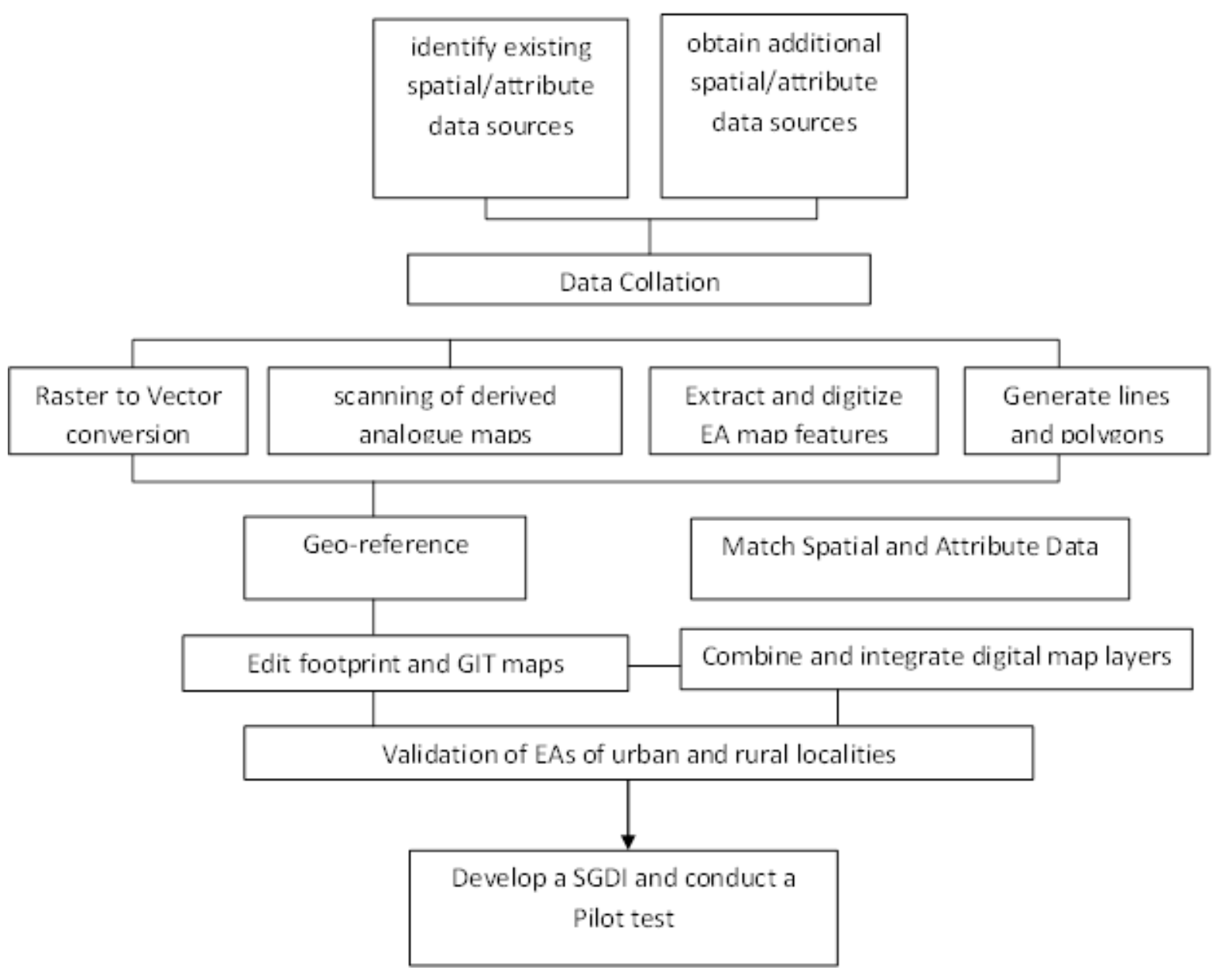

Fig.3: A GIS Framework for generating EAs of urban and rural localities in Enugu State Source: Author

The first step is the identification and collation of all handy spatial and attribute sources of data from hard and soft copies of all current spatial data. The next step is the extraction of EAs from satellite and Google images.

This method is followed by data conversion and generation of lines and polygons then the method of digitization follows suit. Next in line is to match spatial layers and geo-rectify the map before editing and validation and lastly develop a State Geo-Spatial Data Infrastructure (SGDI).
Generated footprint EA map of Enugu Urban and GIT EA map of Ngwo rural areas.

Quick Bird Satellite Imagery of Enugu Urban obtained from the NPC Abuja, was found very useful for the update of land features in the administrative map of Uwani, Enugu urban. The Very High Resolution Image (VHR), did provide the forum for the acquisition of images with highly detailed inventory of land features in Enugu North Constituency. These spatial details were integrated in a hi-resolution software Arc GIS 10.3 to augment obsolete urban maps acquired from the Town Planning Agency. Due to obscurity by dense foliage detailed capture of http://aps.jouranls.ac.za 
spatial features through satellite imagery in the rural area was problematic. To achieve the precise location of dwelling units in Ngwo area we obtained extracts of NPC EA patience ozokwor, ngwo from the satellite imagery and embarked on physical survey i.e. ground-truth method with the use of GPS instrument and an updated topographical map of area. GPS values obtained in the field were transformed to geographic co-ordinates to enable plotting.

\section{Results}

The characteristics of the NPC 2006 EA analogue maps the footprint EA map and the GIT EA map of ngwo are showcased in diagrams accompanied by a map content analysis based on standard cartographic parameters. The uwani and ngwo NPC analogue EA maps were subjected to a map content analysis. The results show that both maps fall short of the 12 spatial quality parameters provided for in Agius (20I5) and Ivan et al. (20I5) respectively viz; completeness, logical consistency, topological consistency, positional accuracy, temporal accuracy, thematic accuracy, mathematical basis, reliability, geometric accuracy, modernity, cartographic design and scientific and social values. A number of cartographic symbolization inconsistencies were observed as follows; total absence of coordinates in all analogue EA maps, scalar accuracy, typographic issues, name placement, line symbolization, point symbolization, bounding line delineation labeling inconsistency and, map design issues.

\section{The EA maps of Ngwo park}

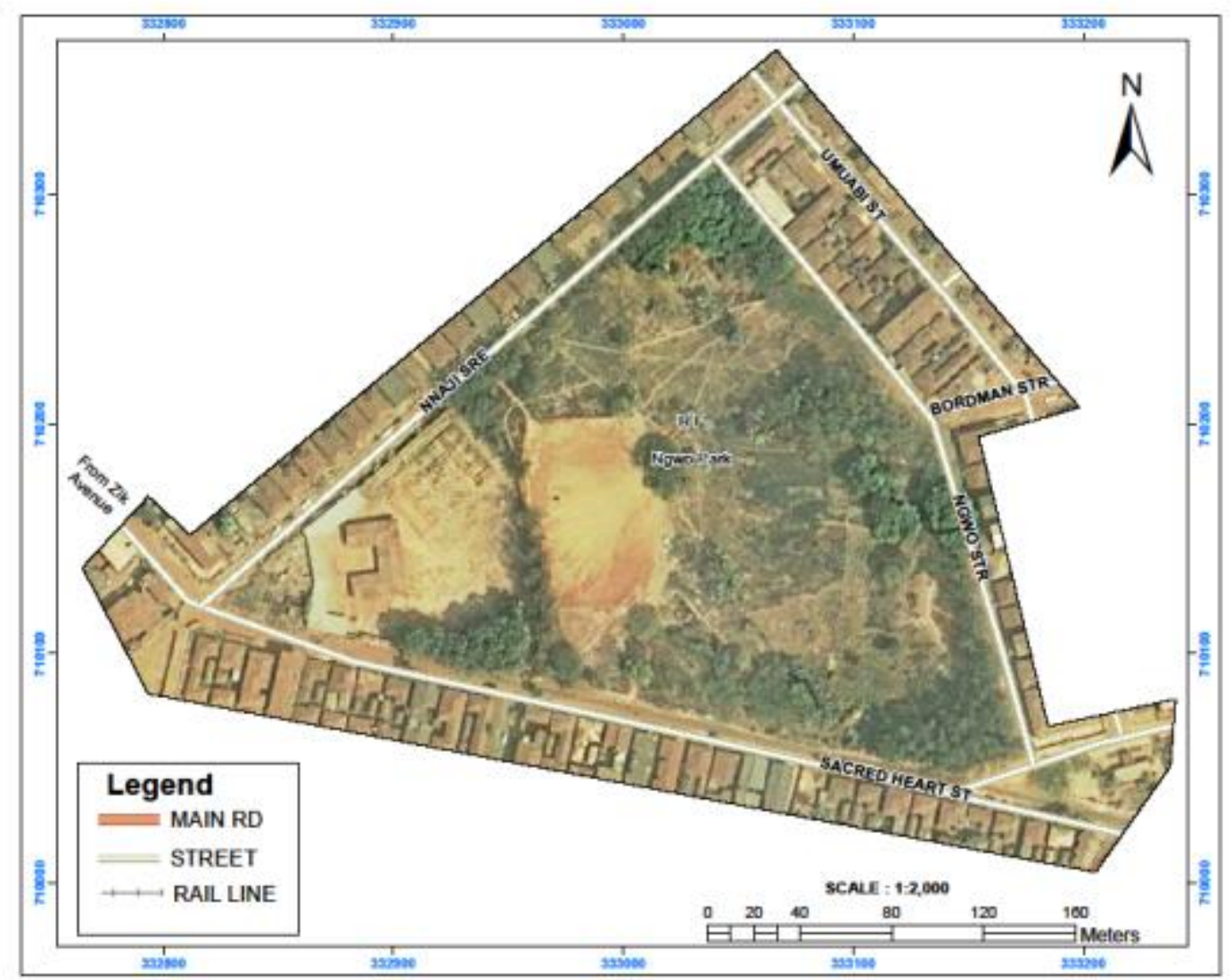

Fig.4(a) Quickbird satellite imagery of EA Ngwo park Enugu Urban-Uwani in Enugu North/South constituency Source: NPC Abuja (2006) 


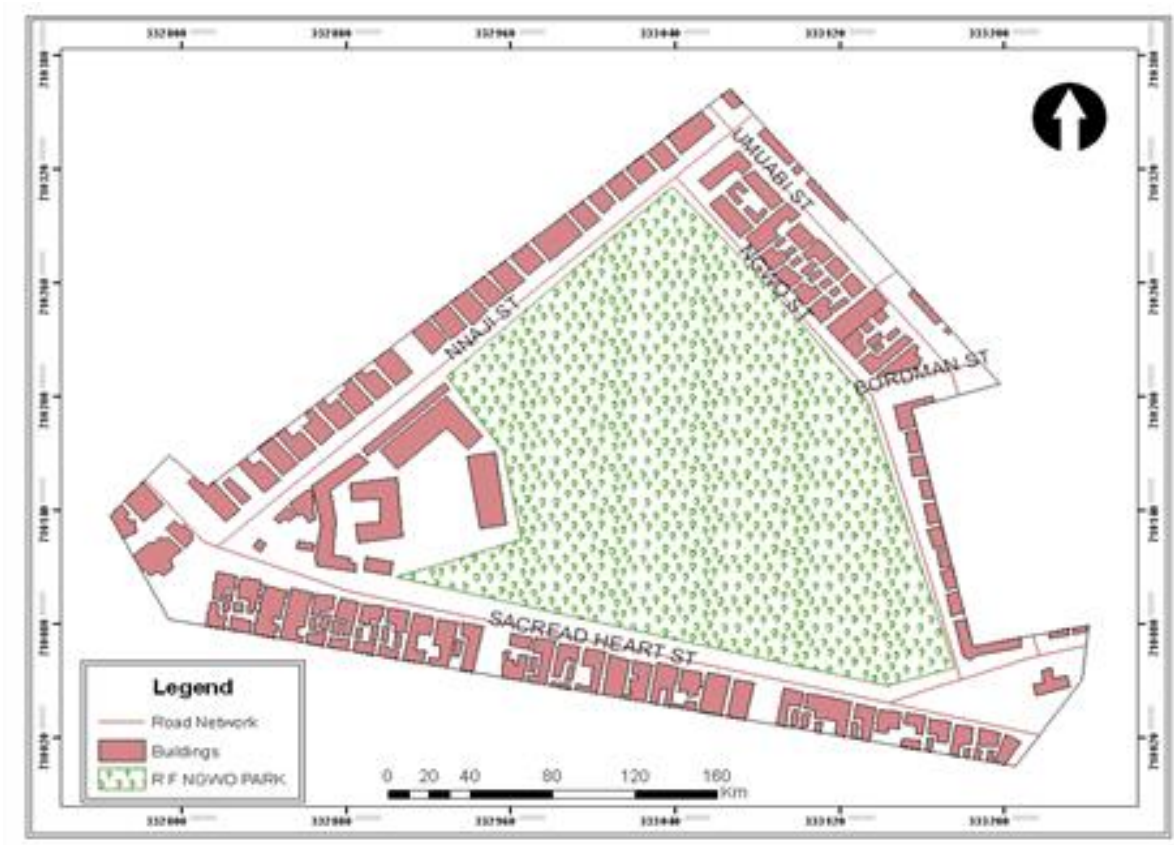

Fig.4 (b) Footprint map of EA Ngwo park, Enugu Urban-Uwani in Enugu Noth/ South constituency Source: Authors fieldwork 2017

Table 3: Analysis of cartographic content of NPC analogue and footprint EA maps of Ngwo park, Uwani

\section{NPC ANALOGUE EA MAP OF NGWO PARK URBAN LOCALITY, UWANI}

Map scale - inaccurate scale evident in the inaccurate length of streets Nnaji is $348 \mathrm{~m}$ and Ngwo $412.5 \mathrm{~m}$ umuabi $243 \mathrm{~m}$, sacred heart is $525 \mathrm{~m}$, ngwo street is $412.5 \mathrm{~m}$ which are all at variqnce with on-ground values coordinates absent on map,

point symbol depiction - residential area wrongly depicted with dots instead of square/rectangular outlines.

Name placement -improper entry of street names e.g. boardman ,agbaja,

Line symbolization - symbol for street/tarred road is at variance with standard map symbol for same Point symbol description -point symbols of haphazard shape applied in the description of buildings on map but do not adequately describe the shape of buildings. e.g .ngwo street

Bounding line- due to wrong scale land area values are disparate with on-ground values

\section{FOOTPRINT EA MAP OF NGWO PARK URBAN LOCALITY UWANI}

Map coordinates are present

accurate lengths of streets Nnaji is $348 \mathrm{~m}$, Ngwo is $345.1 \mathrm{~m}$, umuabi is $174 \mathrm{~m}$, sacred heart is $358 \mathrm{~m}$, ngwo street is $345.1 \mathrm{~m}$

Typographic normenclature of streets are in alignment with features

good name placement in alignment wirh feature on GIT map e.g. sacred heart road

line symbol depiction: the dimension and length of streets/ tarred roads are captured accurately on GIT map e.g. nnaji street, ngwo street

Source:Author's Fieldwork 2018 
Table 4(a) Analysis of cartographic content OF NPC analogue Map OF EA Patience Ozokwor rural locality Ngwo

Map Scale - gross error in scale e.g. inaccurate length of Achalonu Avenue is $448 \mathrm{~m}$. absence of coordintes

Labeling - poor description of place names e.g. Chalonu Avenue and wrong spelling of 'descreption' in key 'description'

Type case - improper use of upper case letter in place name entry. e.g. UKWUABA STREAM

Name placement - names of residents and place names are entered in wrong alignment due to free-hand labelling

Line symbolization - improper description of water body (Ukwuaba Stream), it is the same

linear gauge with boundary line. Linear symbol of road symbol on map is at variance

Point symbolization - poor point feature location and description e.g. building feature location and structure do not match GIT values.

Bounding line - inaccurate delineation of bounding line when compared to GIT map

Map design/omission - poor map layout, absence of co-ordinates

Source: Author's field work 2018

Table: 4 (b) GIT MAP Characteristics Of Ea Patience Ozokwor Rural Locality In Ngwo

-Scale- accurate scale andlength of Achalonu Avenue is depicted as $180.5 \mathrm{~m}$ in GIT map

Labelling-good description of place name evident in GIT map

Type case-Upper case letter instead of mixed case "Ukwuaba Stream " in GIT map

Name placement- names are placed in appropriate locations on map this is evident in GIT map

Line symbolization-good description of water body and good road symbol depiction evident in GIT map

Point symbolization-The GIT map captures buildings in precise location with coordinates

Boundary- accurate boundary delineation evident in GIT map

Geo-reference and Map design-presence of coordinates and good map layout evident in GIT map

Source: Author's fieldwork 2018

The spatial features captured by satellite sensing at both rural and urban wards of Ngwo and Uwani respectively shown in the Footprint and GIT maps reveal high quality spatial details. A professional cartographic analysis of features/ objects in both analogue and digital maps of Ngwo and Uwani wards indicate a number of shortcomings in the analogue map. The most visible is that of absence of coordinates as well as poor scale application.

The NPC EA map checklist audit features used in the study are listed as follows; EA name (EN), EA boundary (EB), starting arrow (SA), legend (LE), building-commercial/residential (BUR), town hall $(\mathrm{TH})$, street name $(\mathrm{SN})$, land mark (LM), locality name (LN), church/mosque(CM), market (MR), power line (PL), survey pillar (SP), fence/wall (FW), gutter (GT), very important persons residence (VIP), schools (SC), water body (WB), rocks (RK), north arrow (NA), hospital/ health centre (HM), roads (RD)- all classes. The NPC EA nomenclature features a 3-digit code for EA I.D e.g. 001 ., 9-digit code for locality I.D. e.g. 00000000 I, a-3 digit code for Local Government I.D. e.g. 0II, a 3-digit code for State I.D. e.g. I I (NPC 2006).

A test was run to determine the frequency of occurrence of the items in the checklist and the results read as follows: A total of 8 EA features namely; enumeration area name, EA boundary, starting arrow, legend, buildings, north arrow and locality name- in the checklist recorded 100\% frequency level, indicating that these features generally feature consistently in all the census EA maps. 3 features recorded average scores of school, $58 \%$, church/mosque $58 \%$ and town hall $50 \%$. 


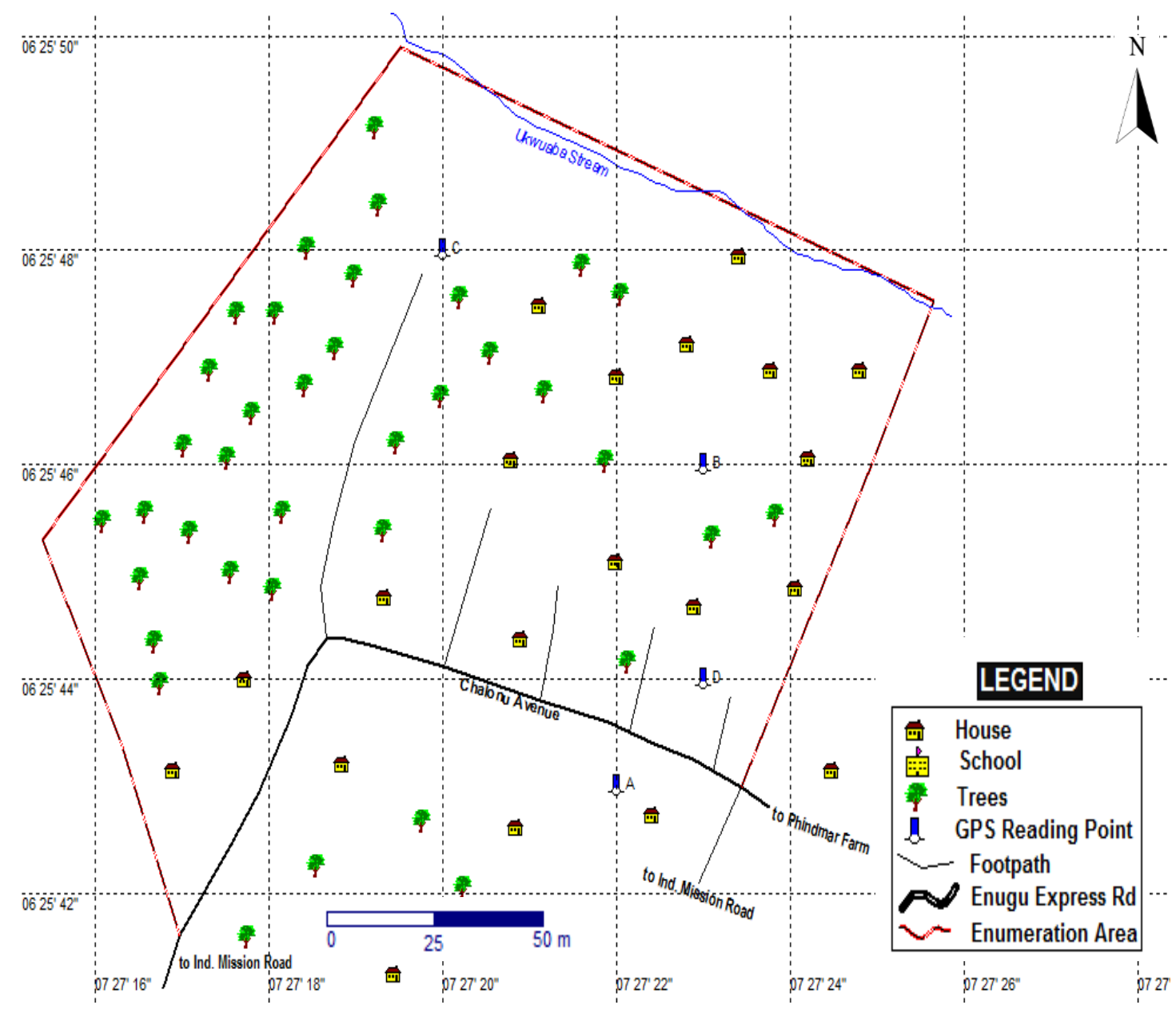

Source: Author's Fieldwork 2017

32 respondents say 'Yes' to sustainability which is $80 \%$ of the sample population while 8 respondents say 'NO' i.e. $20 \%$ of the sample population to sustainability or non-sustainability. Respondents view on the quality of the GIT maps read as follows Poor ( 2 respondents) i.e. $5 \%$ Fair ( 2 respondents) i.e. $5 \%$, Good-( 18 respondents) i.e. $45 \%$, Very Good-( 18 respondents) i.e. $45 \%$

\section{Discussion}

This study demonstrated the GIS method, applied ground-truth method, object identifier method (Blashcke 2013) in matching analogue map features with imagery features and on-ground features. Since the analogue NPC EA maps were devoid of coordinates, on-line topographic data sets and on-line Google imagery/map data sets were generated for the study in an Arc GIS and GPS Track Maker environments. It was an up-scale task in dealing with the rural locality of ngwo. Personal Digital Assistants (PDAs) armed with GPS instruments were deployed to secure location details. The generation of the rural GIT EA map of ngwo was the most challenging exercise.
Enumeration areas are often of varying sizes and normally are delineated based on the shape of the smallest administrative unit which is the household. Sometimes these EAs bestride statutory boundaries and since EAs are not shaped by boundary limits within a constituency, local government, state or region there is a probability that in grouping EAs according to constituencies, a good number of them may have peripheries that extend beyond host boundaries. In this case such EAs need to be downsized as they approach the confines of their boundary so that these EA boundaries coincide with host constituency boundary. In this way it is possible to assign a particular number of EAs to a certain group of constituencies. This paper advocates an integercoded multi-objective genetic algorithm for aggregating EAs with the expectation of obtaining some level of compactness and population/area uniformity among constituencies through an optimization technique that maximizes their configuration in a local/state/national geographic framework. This technique was advanced by Data, Malczewski, and Rui Figueira (20l2). Square-shape and circular-shape compactness of EAs are examined under different scenarios. 
The state of the NPC 2006 spatial data sets is attributable mainly to the dearth of current map data, lack of professional skill, inadequate cartographic instruments and GIS equipment, unavailability of current GIS software and lack of human capacity all combine to throw spanners in the wheel of progress especially in the quality of EA maps. An improvement of this situation can be effected by initially creating a State Geographical Frame comprising basic census geography structures that make up a constituency. e.g.in the urban area we have household, building footprint, enumeration area, ward, locality, federal constituency ( 3 in number) and state constituency ( 8 in number) In the rural area we have a census geography like household,, dwelling unit (compound), kindred, enumeration area, ward, locality e.t.c The next step is to link this up with a National Geographical Frame comprising national census constituencies.e.g. federal and state constituencies of other states in the country. This way the knowledge of the number of demarcated EAs per state, federal constituency, state constituency, locality, ward and enumeration area, as well as the spatial extent of EAs among constituencies in form of shape-files is in public domain. This leaves little room for politicization and manipulation of census outcomes.

Traditionally in the rural communities where kindred ties determine to a large extent and incidentally shape the pattern of dwelling units. The extended family members are found to live in close proximity with each other. The distance that separates these dwelling units from each other is normally within a human voice range.
In some cases EAs within a particular constituency may have their boundaries fall outside constituency boundaries but that can be fixed by applying the method of cell implosion to downsize EAs. The NPC can provide INEC with the necessary population data of adults $18+$ years for election exercises.. The NPC can obtain data on households, EAs, wards, localities and constituency boundaries from the their library and verify such data with same from the Ministry of Lands and Survey. The data sharing ability among agencies like NPC, Independent National Electoral Commission (INEC), National Boundary Commission (NBC) and Ministry of Lands and Survey on population, also paves the way for data verification and validation across sister agencies and allied parastatals. Thiis will assist in plugging loopholes for manipulating census outcomes and also put to rest undue suspicion and allegations over total figures.

All cases of over-enumeration of persons in particular EAs or omission of persons in some EAs due to inaccessibility by census officials which leads to under -enumeration can be checkmated by applying the principle of cross-validation of population figures of wards across agencies. A good knowledge of the population size of the constituencies is key in order to fully validate the population size of component EAs as well as their bounding alignment which is a pointer to the topological accuracy of EA demarcation and boundary delineation exercise. The national geographical frame will provide necessary spatial data to this respect.

This is pertinent because each constituency bestrides 2 or more LGAs.

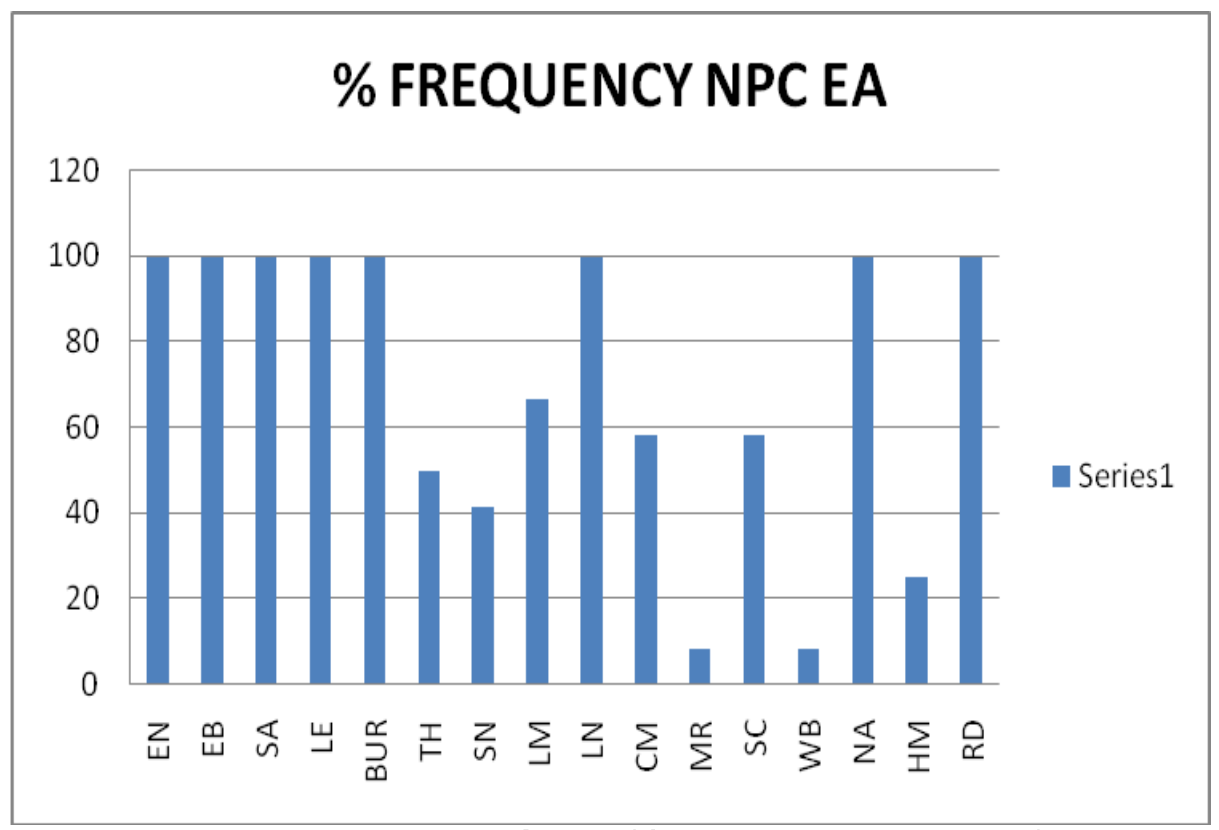

Fig. 6: Percentage Frequency Distribution Graph of Sampled EA map checklist features 
In Enugu State there are 3,223 wards and 13,977 EAs. The average number of EAs per Constituency is I,747. A total of I 7 LGAs make up Enugu State.]

In a multi-ethnic and multi-religious society like Nigeria where population size of each region is important in determining their political and economic status. The elites are often over-zealous about the value and importance of population census, and they always do everything, to enumerate and also engage in various illegalities: electoral violence, falsification and manipulation of population figures (Stallings, 2006).

Since, population figure is the yardstick with which national resources and political representation are shared, each ethnic group battles to inflate census figure in order to keep dominating the other ethnic groups with the advantages of socio-economic and political resources.( Stallings 2006).

Thus census figures in Nigeria has become a kind of legal tender of the nation which have always been used as an instrument of dominance instead of an instrument of even or sustainable development. Demographic manipulation deleteriously rubs off on all facets of a country's national life as a questionable headcount inevitably undermines the totality of socioeconomic development in a country (Odimegwu,20।3).

Odimegwu (2013) further stressed that "unless the census challenge is comprehensively managed and grey areas resolved, Nigeria will continue to wallow in the milieu of socio- economic quagmire arising from blind and unrealizable projections. It is certain that the country is rapidly getting overpopulated. The far-reaching implication of this untoward manifestation is the stretching of the country's collapsing social infrastructure" (Odimegwu, 2013).

National propaganda devoid of ethnicity and religion should take centre stage in all activities bothering on census. It is of the essence at this stage to suggest that tribe and religion be expunged from the census data instrument to douse rising sentiments of religious bigotry and ethnic intolerance. With all the efforts towards EA map data acquisition keyed into a digital-compliant data sharing system, the question of manipulation or falsification of census results will be 'a thing of the past' as component data inputs which are available in public domain can be easily verified by sister agencies, communities, stakeholders and data miners.

Finally when working with GIS EA maps/imageries 5 tips adapted from European Forum for Geostatistics (2008) have to be observed namely:

(a) Each enumeration area is designated by a point address on the monitor. (b) Each enumeration point on the monitor designates an enumeration area address that can be generated by clicking on that point on the screen

(c) EA mapsshould be zoom-compliant. EA maps and imageries are usually saved in PDF format

(d) Maps should be user- interactive and can perform 'add' and 'delete' functions on demand.

(e) EA maps should be print ready for on-line use. In extra large scale mapping where areal unit partitioning is tedious. One of the best ways to ensure detailed depiction of EA population is the application of the dasymetric method. Population density scenarios from EAs can be depicted more accurately by this method which is a graphic technique that transforms geo-spatial data like land cover types into density maps that are linked to certain boundaries like census enumeration areas (EAs),supervisory areas, wards, localities. This method can be used to generate surface based models for aggregated population datasets. (Mennins 2004)

\section{Conclusion}

Accurate headcount can help in future development of Nigeria. When accurate count is institutionalized it will facilitate equitable allocation of resources in different states in Nigeria. This will go a long way in the development of various states in Nigeria as resources are equitably shared. It is recommended that the government should develop policies in the following areas:

(i)The adoption of the I I-tier Census Geography Framework and introduction of the 6-tier EA Template to facilitate improved capture of aggregated population datasets in small area like urban and rural cases. This will set in motion a machinery for a more accurate and complete data set inventory for pilot census survey and mapping especially with regards to generating consistent accurate census figures within a specific 10 -year inter-censal time frame in tandem with sustainable goals $8,9,10$ \& 1 I.

(ii) Application of a digital compliant EA map framework as an alternative to analogue EA free hand map project to meet sustainable targets $9 \&$ I.the mapping of residential, commercial, industrial, recreational, agricultural, pastoral and nomadic uses can be better achieved in areas of spatial accuracy in the dimension of spatial objects and features, topological accuracy, and relationship among EA, ward, constituency, LGAs and State entities.

(iii) Establishment of a State Geo Spatial Data Infrastructure (SGDI) / Data Bank as a derivative of GIS spatial dataset inventory, which provides for capturing, storing, editing, sequential querying, modelling, displaying, analyzing and publishing 
geographically referenced data is in line with the need for population and housing census initiative for the State, and sustainable goals $8,9,|0||| \& \mid$,2 . This will leverage on the initiative for planning and implementation in the area of poverty reduction generally.

(iv) The SGDI will spearhead the initiation of an emapping infrastructure in all National Population Commission and sister agencies in the State that will aid access to the SGDI. These maps are more dynamic and user interactive than 'static' analogue maps. This will facilitate easy update of land use/cover change scenarios and will be beneficial to the ministry of environment, town planning and other allied government agencies, data miners and stakeholders in achieving the sustainable targets 8,9 , $10,11 \& 12$.

(v) The general con-census is to generate a GIS topologically well-matched spatial aggregation procedure of collating data on a constituency-basis to form a Constituency Land Information System ( CLIS) for census round in Enugu State. This will comprise land-cover features for sustainable management of natural resources and land uses types for better informed physical planning of space. For zones with high cattle herder population and large expanse of mechanized farmland area, effort should be put in place made to include all commercial, and private farmlands in an exclusive list. The other group of croplands, game reserves, fallow reserves, bare lands, water bodies like streams, rivers, lakes, ponds e.t.c. can be categorized differently under a different subhead as grazing lands. This is in tandem with the aspirations of sustainable goals I-I5. .

This will also position the State in line with addressing demands for a youth framework for peace-building and equitable resource sharing within LGAs, States and across borders.

(vi)The benefits of the GIS framework will ignite the awareness of developing a Cartography and GIS curriculum as part of the secondary school educational portfolio and as the only option to latch onto the huge benefits of a synoptic spatial feature capture that creates a leverage to meet the sustainable goals $I, 2,8,9,10,1|\&| 2$.

(vii) With the help of a GIS EA framework there calls the need for the establishment of a national policy of GIS mapping in virtually all parastatals, ministries, departments, agencies (especially the Federal Office of Statistics) as a means of unlocking the spin-offs and benefits of GIS, improve mass production of maps, charts, diagrams e.t.c., enable geo-visualization of accurate and wholesome aggregated data sets, eliminate shortcomings experienced in the last 2006 census survey. The awareness of the diverse and complex nature of census database requires a hi-resolution synoptic capture facility like Quick-Bird satellite imagery. That way an easy evolution of a more accountable government, expansion of social policies will further reduce regional inequalities, eliminate cattle herder's conflict, militia insurrection within the State and across geo-politcal zones.

Acknowledgement: We acknowledge the officials of the National Population Commission, Abuja for their co-operation in the area of data provision.

Author contribution: CAO conceptualized the study, obtained and analyzed the spatial data while NOU and ASO structured and edited the work.

Funding: None

\section{Conflict of interest: None}

\section{References}

Agius, C 2015. "National Mapping \& Cadastral Practices" International Workshop on Spatial Data and Map Quality. www.eurogeographics.org/sites.../SDMQ I5...

Akinyoade, A., Appiah, E. and Asa, S 2017. "Censustaking in Nigeria: The good, the technical, and the politics of numbers" Etude de Population Africaine/African Population Studies 3I (I)

Amori, A. A 200I. 'Towards a National Program on Census Mapping in Nigeria: Fundamental Issues and Policy Options in Techniques and Policy issues in Census and Census Mapping' (ed) Nsofor, G.N., Adeyemi, S.A. and Nwaogboso N.K. Nigerian Cartographic Association, University of Lagos

Blaschke, J. 2013. "Object-based Image Analysis: A New Paradigm in Remote Sensing" ASPRS, Annual Conference, Baltimore, Maryland, March 24-28

Boserup, E (1981): Population and Technological Change: A Study of Long-Term Trends. University of Chicago Press, Chicago Data, D., Malczewski, J. and Figueira, J. R 2012. "Spatial Aggregation and Compactness of Census Areas with a Multi-objective Genetic Algorithm: A Case Study in Canada"'Environment and Planning B: Planning and Design 39 (2): 376-392.

Diamond, L. J 1998. "Class, Ethnicity and democracy in Nigeria: The Failure of the First Republic." Syracuse, New York: Syracuse University Press: |3|-|33

Dinar, I. Kljucanin, S. and Posloncec-Petric, V 2015. "Large Scale Topographic Maps:Generalization and Visualization Based on NewTechnology". Geodeticlist.2, I89-198.

EDAC 2008. "New Mexico LUCA "Undercount Analysis" 
www.https://edac.unm.edu/2008/I 0/new-mexicoluca-undercount-analysis

Egharevba, M 2017. 'Demographic dynamics, governance and the attainment of democratic development: The case of Nigeria' African Population Studies, 3I (2)

Enieayejuni, A. T. and Agoyi, M 20II. "A Biometric Approach Census and National Identification in Nigeria: A Prerequisite for Planning and Development" Asian- Transactions on Basic and Applied Sciences I (05)

European Forum for Geostatistics 2008. 'GIS for Enumeration Areas Planning' CSB of Latvia in cooperation with State Land Service of Latvia. Workshop Bled, Slovenia October I-3.

Ezeah, P. lyanda C., and Nwangwu, C. 2013. "Challenges of National Population Census and Sustainable Development in Nigeria : A Theoretical Exposition". Journal Of Humanities And Social Science (IOSR-JHSS) I8 (I): 50-56

Eze, C.G and lgbokwe, J. I 2004. "Delineation and Management of Enumeration Areas in Census Operations" http://beta.gisdevelopment.net

Fasona, M.and Omojola, A 2009. "Land cover change and land degradation in parts of the south-west coast of Nigeria." African Journal of Ecology 47 (5I) $30-38$

FEMA (2015). www.fema.gov/hazus · I-877-FEMA MAP Federal Environmental Management Agency Geo-Space 2002. "Census Cartography" http://www.census.cartography.pdf

Geo Spatial Resource Portal, 2006. "Addressing the challenges associated with census mapping in Africa."

http://beta:gisdevelopment.net/application/miscell aneous/maf06 25a.htm

Hardin, P.J. and Shumway, J.M 2008. "Intra-Urban Population Estimation with Remotely Sensed Imagery: A Developing World Perspective" Geography Compas 2 (3) 770-774.

Ivan, I, Lonsky, M.G.U. and Anja H 20I5. "Complex Estimation of Quality of Cartographic Products". International Workshop on Spatial Data and Map Quality. January 20-2I, Valetta, Malta

Kruger,T.A.and Fitch, C.A 20I8. "Interoperable and accessible census and survey data from IPMUS" Scientific Data 5. US National Library of Medicine, National Institute of Health

Mberu, B. and Eze, A 2017. 'The Population Factor and Economic Growth and Development in subSaharan Countries' African Population Studies $3 I(2)$

Mennins, J. 2004. "Generating Surface Models of Population Using Dasymetric Mapping" The Professional Geographer 55 (I)
Mokgokolo, J.J 20II. "Challenges experienced with the demarcation of Enumeration Areas for Census 20II", Geography Division Statistics South Africa, Pretoria, South Africa. africangeodownloads.info $>128$ mokogkolo.

McKelvey, V.E 20II. "LandsatProgram-History" http://Landsat.gsfc.NASA.gov/about/landsat l.html Morris, C .(197I): Writings on the General Theory of Signs, Mouton, The Hague, Paris.

National Population Commission, 2006. National Population Commission Manual NPC Abuja.Adobe Reader

National Population Commission, 2007. Micro Products Limited, Abuja

http://www.population.gov.ng.news.php detail $=18 \mathrm{htm}$.

National Population Commission, 2007. "Federal Government of Nigeria, Official Gazette of 2006 National and State Provisional Census Figures." 24 (94) Federal Government Printer Lagos, Nigeria.

Nexhmije, L. Ledjo, S. Ervin, S. \& Mirela, D 2014. "Implementation of GIS Technology to Support Population Census Operations in Albania" www.instant.gov.al/media...pdf Management of Statistical Information System National Institute of Statistics, Albania.

Nwajiuba, C.U 20I I. " Introduction-Climate Change Adaptation Strategy Report- (CCA NIGERIA". Building Nigeria's Response to Climate Change(BNRCC)

Nigerian Environmental Study/Action Team (NEST), Ibadan, Nigeria

Obono, O. and Omoluabi, E 2014. "Technical and political aspects of the 2006 Nigerian population and housing Census" Etude de Population Africaine/African Population Studies 27, (2)

Odimegwu, F. F 2013.||Nigerian Census Challenge: Our Report || The Sun IIth August 2013, P.I [15].

Ofomata, G.E.K (ed) 1975. Nigeria in Maps: Eastern States Ethiope Publishing Corporation, Benin City.

Olorunfemi, J.F 200I. "Better by Far" 5 I st Inaugural Lecture of the University of Ilorin, 29th November.

Onyekwelu, C.A. and Ochege, F.U 20I5. "Census Block Maps Used for 2006 Pre-enumeration Survey in Enugu Urban : A Critique "Nigerian Journal of Cartography \& GIS 10, (I). Nigerian Cartographic Association

Onyekwelu, C.A. (2006): Iconological Issues in Cartography Mike Social Press, Nsukka.

Orongo, N.D 2013. "GIS-based Cartographic Generalization in Multi-Scale Environment:Lamu County." Unpublished Master's Project, 
Department of Geo-Spatial and Space Technology, University of Nairobi, Kenya.

Pai, H.H 2013. "Census Taking in NigeriaChallenges and Prospects"Workshop on the Review and Evaluation of the 2006 PHC, Minna.

Tiede, D, Lang, S., Albretcht, F., Holbing, D 2010. "Object Based Class Modeling for CadastreConstrained Delineation of Geo-Objects".Photogrammetric Engineering and Remote Sensing, 76: 193-202

Samreen, A 2013. "Perception in Visualization" extracted from www.ics.uci.edu $>$ vispercep $>$ samreenaccessed $3 r$ dFebruary, 2015

Soneye, A. and Akintuiyi, A 2013. "Nigeria Remote Sensing and Topographical Mapping", 1937-2010: A Critical Appraisal Lagos.Journal of Geographical Science 2 (I): 15-27

Srivastava, S.K 2012. "Workshop on Cartography and Geo-visualization" Brisbane Convention and Exhibition, Queensland Survey and Spatial Conference (QSSSC) Centre, 13th-I4th September.

Srivastava,S. K 2013. "Threshold Concepts in Geographical Information Systems:a step towards conceptual understanding." Journal of Geography in Higher Education, 37:3,367-384

Stallings, W (2006): Cryptography and network security, New Jersey, US: Prentice Hall
Robinson, A. H. and Petchenik, B.B. (1976): The Nature of Maps University of Chicago Press, Ltd., London

Robinson, A.H., Sale, R.D. and Morrison,J.L. (1978): Elements of Cartography University of Chicago Press, London.

Statistics South Africa (20II). Census in brief /. Census 20II Pretoria, 20I2.

Stoter, J., Post, M., vanAltena,V., Nijhuis, R., and Bruns, R 2014. "Fully Automated48. Generalization of a map of 1:50k from I: I 0k data." Cartography and Geo-information Science. 4I(I): I-13.

Thomas Brinkhoff 2015. www.citypopulation.de www.ng.undp.org.home.sdg-overview

Wu, C. and Murray, A.T 2007. "Population Estimation Using Land Sat Enhanced Thematic Mapper Imagery" Geographical Analysis, 39: 26-43.

Wilmoth, J 2015. "World Population Expected to Reach 9.7 billion by 2050, with most growth in developing countries especially Africa-says UN 2015 : A Time for Global Action For People and Planet" Press Release from the United Nations Department of Public Information.

Zyszkowska, W 2015. "Map perception, theories and research in the second half of the twentieth century" Polish Cartographic Review 47 (4): I7919 